\title{
EXILIO, EMIGRACION Y DESTIERRO \\ EN LA OBRA DE DANIEL MOYANO
}

\author{
POR \\ JOSE LUIS ROCA MARTINEZ - VIRGINIA GIL AMATE \\ Universidad de Oviedo
}

En là década de los setenta América no habra escapado aún de la estrecha trilogía que Alfonso Orantes pronosticaba al intelectual de estos lares. El destino de muchos escritores, y no digamos de sus personajes, se debatía entre el destierro, el encierro o el definitivo entierro. Argentinos, uruguayos, chilenos y brasileños se unían a sus antecesores paraguayos y al largo éxodo de centroamericanos y cubanos. Este interminable trasiego corroboraba por enésima vez la admonición de Orantes y cumplía con la "tradición de exilio" que Torres Fierro ${ }^{1}$ observa en las letras hispanoamericanas.

En 1976 Daniel Moyano pasaba a engrosar la nómina de escritores desnaturalizados (voluntariamente, por razones de diversa índole, acuciados por las circunstancias o forzados por el régimen político) de su tierra natal. El exilio no parece haber sido, en su avatar concreto, nada fácil.

Mientras Augusto Roa Bastos, que en su día fue decano de la diáspora, dice descubrir al hombre universal una vez fuera de su país ${ }^{2}$, e indudablemente la insularidad de las letras paraguayas termina con el exilio de sus autores, el caso de Moyano es diferente. La expulsión es vivida no ya como una experiencia dolorosa sino anquilosante por todos sus personajes y no fue demasiado justa, durante largos años, en lo que atañe a la difusión de su obra.

No cabe duda que un suceso de estas características carece de una solución unívoca para todos sus protagonistas. Por ejemplo, Julio Cortázar y Eduardo

\footnotetext{
1 "No es casual que en la literatura latinoamericana haya una larga tradición de exilio, a veces interior, a veces exterior, a veces voluntario, a veces impuesto. Es una constante que también se vincula al desarrollo de la literatura moderna, toda ella signada a fuego por el exilio" (Danubio Torres Fierro, Los territorios del exilio, Barcelona: La Gaya Ciencia, 1979, 38).

2 "Me interesa el hombre universal que es la gran lección que yo le debo al exilio. Nunca podré quejarme de mi exilio porque fue para mí una gran escuela" (Francisco Tovar, "Acordar la palabra ...", en Augusto Roa Bastos: Premio de Literatura en Lengua Castellana "Miguel de Cervantes 1989"' Barcelona: Anthropos y Ministerio de Cultura. Madrid: Centro de las Letras Españolas, 1990, 69).
} 
Galeano abogan por aferrarse a los factores positivos. El autor argentino apelaba a que el campo de abandono que han pretendido los expulsadores se torne en un revulsivo del compromiso en los expulsados ${ }^{3}$. Pero no sólo eso. Aún consciente de dar un paso en el vacío, pide que la literatura del exilio se aleje de las notas trágicas, de la pérdida, de la nostalgia o de la furia para que sus mismos cimientos sean positivos - ¿ ¿Y si los exiliados optaran también por considerar como positivo ese exilio? ${ }^{n 4}$. En parecida tesitura se sitúa Galeano: la literatura del exilio debe partir de lo positivo, esta vez con un fin utilitario claro, el aporte que el escritor pueda hacer a la hora del regreso ${ }^{5}$.

Mientras unos autores han hecho del exilio uno de los centros neurálgicos de su obra (caso de Mario Benedetti) otros no dejan rastro alguno por larga que haya sido la ausencia (caso de Augusto Monterroso). Entre unos y otros surge la figura de Moyano que ha retratado todas las variantes del destierro y en ninguna de ellas ha dejado traslucir algo, el más leve vestigio, positivo.

\section{EXILIO INTERIOR}

En 1974, con la edición de El estuchedel cocodrilo ${ }^{6}$, Moyano hacía su primera incursión en el tema de la represión política sufrida dentro de las fronteras de un país. Más tarde aparecerian las novelas $E l$ vuelo del tigre ${ }^{7}$ y $E l$ trino del diablo ${ }^{8}$ (sobre todo la segunda versión y los relatos que la acompañan), que entran de lleno en la plasmación de ese mundo cerrado que supone el exilio interior.

El lugar donde se ubica la acción en EVT, Hualacato, es transformado en cárcel por obra y gracia de los Percusionistas. Esta geografía de la imaginación es a la vez una región inequívocamente americana. Sigue la senda de la Comala de Juan Rulfo situada "sobre las brasas de la tierra, en la mera boca del

\footnotetext{
${ }^{3}$ Para Cortázar era imperioso realizar una revisión del concepto de exilio para cambiarlo "de la categoría de disvalor estéril a la de valor dinámico" "El exilio combatiente", en Argentina: años de alambradas culturales, Buenos Aires: Edit. Galerna, 1970, 40). " Julio Cortázar, "América Latina: exilio y literatura”, Argentina, 20.

- "Así amplío el campo de mi mirada y así voy encontrando claves de creación y de orientación que podrán ser de alguna ayuda, tarde o temprano, cuando llegue la hora del regreso y haya que regar las tierras que las dictaduras están arrasando" ("El exilio, entre la nostalgia y la creación", en Nosotros decimos no. Crónicas (1963/1988), Madrid: Siglo XXI Editores, 1989, 253).

${ }^{6}$ Daniel Moyano, El estuche del cocodrilo, Buenos Aires: Ediciones del Sol, 1974. Citaremos $E D C$.

${ }^{7}$ Daniel Moyano, El vuelo del tigre, Madrid: Legasa, 1981; también Barcelona: Plaza y Janés, 1984. Citaremos EVT.

B Daniel Moyano, El trino del diablo, Buenos Aires: Sudamericana, 1974; El trino del diablo y otras modulaciones, Barcelona: Ediciones B, 1988. Citaremos ETD1 y ETD2, respectivamente.
} 
infierno"9 y del Macondo de Gabriel García Márquez aislado del resto del mundo por pantanos intransitables. El espacio escogido por Moyano es mítico a todas luces, una tierra que sufre periódicamente la violencia y cuya soledad es infinita.

Nada más comenzar la novela, el narrador localiza la acción al otro lado del paraíso - "Hualacato, ese pueblo perdido entre la cordillera, el mar y las desgracias" ${ }^{\text {"10 }}$. Es la misma región donde se ubica "Una guitarra para Julián"11, en un pueblo innominado perdido entre sierras peladas, en una latitud lejana, en las antípodas de los núcleos de poder.

A su localización remota se une un aislamiento impuesto. Las fronteras del país, los límites de la provincia y el término de la ciudad son factores primordiales en la construcción del férreo muro que enclaustra los horizontes de las víctimas. A ellos hay que sumar varios elementos que, en el primer capítulo de la novela, preludian la prisión en la que se va a transformar la ciudad: la radio (símbolo del espacio cerrado. Si por un lado es el cordón umbilical que une Hualacato con el mundo, por otro, ese único conducto redunda en la soledad de los hualacateños a la hora de la represión ${ }^{22}$; la despedida de aquellos que emprenden el éxodo que suponen los primeros balbuceos de una etapa de pérdidas continuas; las reaccionesinstintivas de los animales que huelen el enrarecimiento del ambiente; y la imposibilidad de protegerse en parte alguna. Ese peligro total y persistente, esa inexistencia de un escondite, de un lugar seguro, son los parámetros de la represión que pinta Moyano.

El medio vital se va adulterando, una atmósfera de absurdo lo recorre. Los pacíficos ciudadanos son ahora sospechosos, perseguidos y reos al fin, por un "pase mágico" de los Percusionistas. Las calles han perdido su orientación primera, los bares son "lácteos" y numerosos "turistas" de aspecto agresivo recorren el pueblo.

9 Juan Rulfo, Obra completa. El llano en llamas. Pedro Páramo. Otros textos, prólogo y cronología de Jorge Ruffinelli, Caracas: Biblioteca Ayacucho, $\mathrm{n}^{\mathrm{Q}}$ 13, 1977, 111.

${ }^{10} E V T, 7$.

${ }^{11} E D C, 33-37$.

${ }^{12} \mathrm{La}$ comunicación de las ondas hertzianas no tiene efecto de retroalimentación en esta narrativa; asi, la radio funciona en toda la obra de Moyano como signo de la soledad. En relatos como "Cantata para los hijos de Gracimiano" (EDC, 39-51) y "Para que no entre la muerte" (EDC, 53-63) se constituye en el eje de separacion entre el territorio habitado por los personajes, marcado por la miseria y la marginación, y de "otro mundo" de opulencia. En Tres golpes de timbal, hace que en la region asolada de Minas Altas se oigan los sonidos de las "ciudades distantes" (Tres golpes de timbal, Madrid: Alfaguara, 1989, 171; también, Buenos Aires: Sudamericana, 1990; citaremos TGT). Por medio de ella los personajes se asoman a la realidad politica gestada en otras partes. En EVT y ETD (el capitulo octavo de ETD1 se titulará "La terrible guerra de las radios", 42-47) quedarán convertidos en víctimas atonitas de golpes de estado que no entenderán más allá de lo escuchado en la radio. La importancia que nuestro autor le otorga al símbolo queda también de manifiesto en el prólogo que realiza a La señorita Estrella y otros cuentos de Juan José Hernández (Buenos Aires: Centro Editor de América Latina, 1982: I-V). 
Ese es el marco externo pero la acción directa sucede en el domicilio de los Aballay. Al reducirse el espacio de la narración se incrementa la sensación de claustrofobia. Así, si Hualacato es una cárcel, cada casa será una celda y cada ciudadano un preso vigilado por un Percusionista.

Ante la destrucción del presente y la carencia de esperanzas, los Aballay se refugian en los recuerdos. Buscan las antiguas fotos familiares para reencontrarse en algún momento feliz. El espacio del pasado será el bastión de espera mientras se aguarda la ida de Nabu. Este es uno de los puntos fundamentales del exilio interno que Moyano plantea, apelar a la memoria de cuando la casa era un hogar y el pueblo un marco hospitalario.

Roa Bastos ha calificado la situación del exiliado interno de "autismo ${ }^{\text {p13 }} \mathrm{en}$ cuanto a la imposibilidad de comunicación; en la misma línea se manifiestan Bareiro Saguier, llamándolo "exilio del silencio" ${ }^{\text {"4 }}$ y Moyano, que en sus textos hace referencias continuas a la castración del lenguaje, a la pérdida de la palabra y de la capacidad de comunicación ${ }^{15}$. El silencio impuesto implica que se sufrirá en soledad, que se adulterará día a día la realidad cotidiana sin poder denunciarlo, que no habrá esperanza alguna puesto que no podrán invocarla. Los "ruidos" de Hualacato son "inaudibles" y los gritos de los Aballay se expanden hacia dentro ${ }^{16}$. Mientras en $*$ Kafka $72 \star^{17} \mathrm{y} * \mathrm{El}$ poder, la gloria, etc.. ${ }^{18}$ la incomunicación parte de que cualquier palabra puede ser malinterpretada. El segundo relato comienza con una frase que describe ese mundo cerrado de delación y enajenación: "Ultimamente en esta ciudad casi todos los habitantes son policías; y un gran número de casas no identificadas, juzgados" ${ }^{\text {"19 }}$.

Que el hombre es un ser agresivo y cruel por naturaleza es una idea dominante en esta narrativa, pero es en el espacio del exilio interior donde el pensamiento del Leviatán parece encontrar su acomodo más certero. La depredación del hombre por el hombre es un hecho presente en $E D C$, en relatos

13 "El exilio interior se percibe bien en situaciones muy extremas de opresión, de opresión pretoriana, política, social, en que uno pierde absolutamente la posibilidad, el don supremo de ser humano que es la palabra, la posibilidad de comunicación. Y al perder esto se vuelve uno un autista. Empieza a ensimismarse y a perder" (Tovar, 70).

14 Rubén Bareiro Saguier, "Escritura y exilio", en Novela y exilio. En torno a Mario Benedetti, José Donoso y Daniel Moyano, coordinador Olver Gilberto de León, Montevideo: Signos, 1989: 21; citaremos Novela y exilio.

${ }^{15}$ En "Una guitarra para Julián" ( $\left.E D C, 33-37\right)$ los personajes pierden la facultad de "alegrarse" y dejan de comunicarse entre ellos; en "El estuche del cocodrilo" (EDC, 5-9) la familia protagonista vive aislada de sus vecinos, con los que no establecen trato alguno, por ser auténticos "sospechosos" al convivir con un cocodrilo.

16 "Más que un olor parece un ruido, pero in audible, un soplido agregando al silencio, como si los Aballay en su conjunto estuviesen gritando para adentro, oliendo para adentro", EVT, 49.

${ }^{17} \mathrm{EDC}, 79-84$.

${ }^{18} E D C, 99-110$.

${ }^{19} E D C, 107$. 
como *Tiermusik ${ }^{20}$ y en EVT. Curiosamente, en esta última novela, Nabu pretende siempre desviar la responsabilidad de la represión de su propia persona a los asustados Aballay. Estos son víctimas pero además "deben” ser cómplices ${ }^{21}$. Moyano crea un ambiente de neurosis permanente. El personaje se siente observado, es espiado, es sospechoso, y en la misma medida sospecha. Cuando constata que su condición es compartida por sus congéneres, que la enajenación es global, pensará que la suya no es más que la situación de un preso en una inmensa cárcel, con la salvedad de que la desproporción de esta hace imposible la huida:

En cuanto a mi situación actual, me encuentro aparentemente en un callejon sin salida. Digo aparentemente porque he visto que en el resto del mundo a mi alcance las cosas son más o menos parecidas, o sea que el callejon es tan grande que parece en realidad una salida, la unica ${ }^{22}$.

\section{EXILIO EXTERIOR}

En Libro de navíos y borrascas ${ }^{23}$, la novela del exilio externo, una carta enviada por un amigo riojano le confirma a Rolando que su expulsión ha sellado una parte de su vida pero aún así es preferible a la represión sufrida en el país:

Lo bueno de todo esto es que tu final fue bien elegido. Te fuiste a tiempo, ignorando lo que vendría después. Es un final con privilegios ${ }^{24}$.

Esa es la doble situación que deberán asimilar los navegantes del Cristóforo Colombo, el exilio es un corte brutal (un "final") que sin embargo deberán aceptar como "privilegio". Lo que en Cortázar y Galeano era una postura de combate, en Moyano es una triste imposición de las circunstancias. Sus personajes, caracterizados por estar "bamboleándose" al pairo de los acontecimientos, se han quedado con lo malo, escapando de lo peor, por simple azar. En el barco deberán asimilar que en un mismo movimiento, repentino e involuntario, "mueren" y "nacen" estigmatizados.

La ruptura es el rostro del exilio externo. Rolando, como los protagonistas de $"$ Golondrinas ${ }^{25}, *$ Desde los parques ${ }^{26} \mathrm{y} *$ María Violín ${ }^{27}$, deben enfrentarse

\footnotetext{
${ }^{20}$ ETD2, $198-200$.

21 “... y ahora mismo me van a decir quiénes son las otras tías de las fotos, la rea Céfira la rea Marcelina la rea Francisquita todas juntas, y ustedes con el Cachimba cavarán sus tumbas" (EVT, 112).

22 "El poder, la gloria, etc.", $E D C, 109$.

${ }^{23}$ Daniel Moyano, Libro de navtosy borrascas, Buenos Aires: Legasa, 1983; Edics. Noega, Gijon, 1984; citaremos por la edición de Gijon, $L N B$.

${ }^{24} L N B, 298$.

${ }^{25}$ ETD2, 177-187.

${ }^{26}$ ETD2, 133-151.

${ }^{27}$ Daniel Moyano, “María Violín”, El Pats Semanal 549, Madrid, 18 oct. 1987: 52-61.
} 
a una existencia partida en dos mitades irreconciliables. A través de la imagen de un violín abandonado se expresa la pérdida en $L N B$. El Gryga es el símbolo de la vida que se abandona, como el barco de la que se inicia - Porque la quiebra, y la caída consiguiente del Gryga, dividió mi tiempo de vivir en un antes y un después ${ }^{\text {"28 }}$. Rolando se debate en el abismo abierto entre el "antes" y el "después". En estas simas el personaje está condenado a desarraigarse de su sociedad, de la realidad cotidiana, de un determinado idioma ... la pérdida es constante y ha llevado a Héctor Tizón a denominar gráficamente a este proceso "el desgarrón" del contorno social ${ }^{29}$.

El exilio es dicotómico, tiene dos caras que miran simultáneamente al pasado y al futuro aún inexplorado. El narrador de $L N B$ hace constantes referencias al "destete" de Rolandoy del resto de sus compañeros, un nacimiento brutal a una nueva vida donde está presente el recuerdo de lo que se fue y ya nunca se recobrará. El protagonista se asemeja entonces al héroe demediado de Italo Calvino - no sé si soy como esas viboritas ciegas que al cortarlas con la pala al cortar la tierra siguen moviéndose independientemente cada una por su lado"30 - ausente esta vez de ironía alguna. Al no poder vivir a un tiempo dos vidas paralelas, en dos planos temporales y en dos espacios distantes, Rolando está obligado a asimilar el corte, la ruptura, el desgarrón del exilio como una cicatriz imperecedera que además marca un renacer no exento de amargura.

La "nueva" vida se inicia a bordo de un barco y en medio del océano. Este espacio, amplísimo y extraño, es el preludio de la geografía venidera. Dos figuras ausentes acompañarán a Rolando en la travesía: el recuerdo de su abuelo emigrante y una mujer soñada. Sara Bonnardel los considera "guías que lo conducirán a través del laberinto del exilio" ${ }^{\text {331. }}$

${ }^{28} L N B, 51$.

${ }_{29}$ "He salido muchas veces del país, incluso he vivido afuera muchos años, y en ningún momento sentí esto que uno siente cuando se sale de otra manera, exiliado o autoexiliado: es el desgarrón con la pérdida de identidad, con la pérdida del contorno con el cual tu viste un trato cotidiano, en el cual estabas integrado" (Héctor Tizon, "Sentirse fuera de la patria”, Clarin, Buenos Aires, 7 enero 1982.

${ }^{30} L N B, 71$.

${ }^{31}$ Otorga dos funciones especificas a uno y otro; al abuelo ser el portador de la memoria de las tierras hacia las que se dirige el nieto; mientras Nieves es "la representación del otro, del desconocido que hay que cautivar para apropiarse de su tierra y de su cultura" (Sara Bonnardel, "Libro de navios y borrascas: los aprendizajes del exilio" en Novela y exilio, 99-100). Nosotros disentimos del análisis propuesto de la mujer imaginada. Creemos que Nieves forma parte de esa cohorte de figuras femeninas que pueblan la obra moyaniana de las que son buen ejemplo Teresa en "La puerta" (Artistas de variedades, Córdoba: Assandri, 1960, 51-62; citaremos ADV; y El monstruo y otros cuentos, Buenos Aires: Centro Editor de América Latina, 1967, 13-19; citaremos EM) o Beatriz en Una luz muy lejana (Buenos Aires: Sudamericana, 1967 y Córdoba: Alción, 1985; citaremos por la edición de Córdoba, $U L M L$ ). Estas simbolizan la belleza, to que se desea alcanzar, esa "otra vida" maravillosa que siempre se sitúa en la vereda opuesta al personaje protagónico. Nieves es la esperanza de felicidad que todas las criaturas de esta narrativa fabrican a base de sueños. 
Rolando, en su presente cortado y apenas asimilado, sueña un futuro feliz al lado de Nieves en España y se apoya en la figura del abuelo español para sentirse menos ajeno cuando pise la nueva tierra. De la superposición temporal que el protagonista realiza en su particular viaje interior hacia el exilio, es buen ejemplo el capítulo VIII ${ }^{32}$. En él se mezclan el abuelo emigrante y el nieto exiliado; el barco rumbo a América - "Un cacharro cualquiera, una basura que sirvió para traerlo ${ }^{133}$ - y el Cristóforo Colombo dirigiéndose a Europa; el Hotel de Inmigrantes de Buenos Aires y el presagio de un desembarco poco idílico.

Desde los albures de la obra, Rolando establece una relación entre los dos barcos, dibujando un pentagrama con dos blancas, cuyo sonido era el de las sirenas, y afirma que entre ellas "sólo había que poner una línea de prolongación ${ }^{\text {"34. }}$. De este modo se unen los destinos del abuelo y el nieto; y el viaje pasado de ida con el presente de vuelta. Estamos ante lo que César Fernández Moreno denominó la "desinmigración"35 a Europa y que en otras ocasiones hemos ilustrado con un juego entre el pensamiento hegeliano de América como continente del porvenir y el presente de diáspora americana hacia Europa ${ }^{36}$.

Pensar que se "regresa", que se "vuelve", aminora el dolor de la expulsión y la desnudez del desarraigo. Pero no sólo eso. Rolando está buscandola manera de terminar con las migraciones periódicas y encontrar por fin una tierra segura. A lo largo del texto ha mencionado las condiciones de violencia de América, el caso particular de Argentina y dentro de ella la marginación endémica de su tierra, La Rioja. Lo cual constituye el marco físico que ha propiciado el trasiego.

Al volver los ojos hacia el abuelo, Rolando hace que su exilio se inserte en un marco ancestral de destierro y, por supuesto, a la constatación de que la "desinmigración" es una manera de denominar el fenómeno, de estudiarlo y de acercarse a él, pero nunca una forma de aprehenderlo puesto que tal fenómeno no existe, "no se puede volver como no se puede nacer dos veces"37. Quizás ese retorno sea sólo halagüeño "para algunos", como sugeríamos, pero jamás para un personaje moyaniano.

\footnotetext{
${ }^{32} L N B$, cap. VIII, “Zampan6”, 149-157.

${ }^{33} L N B 156$.

${ }^{34} L N B 17$.

35 César Fernández Moreno, "De l'immigration a la désimmigration", Les Temps Modernes: 420-421, juillet-aout, 1981.

${ }_{36}$ "Sabido es que los tiempos modifican los caracteres de los pueblos y a la decimonónica frase hegeliana, América es el continente del porvenir, sucedió nuestro porvenir está en América y ahora, quizás pueda afirmarse el porvenir está en España, para algunos" (José Luis Roca Martínez: "Emigración y Literatura", Asturianos fuera de Asturias, Actas de las IV Jornadas Culturales de Aller, Mieres, 1988, 108. También Galicia y América: el papel de la emigración, Actas de las V Xornadas de Historia de Galicia, Servicio de Publicaciones de la Diputación de Orense, Orense, 1990, 71-94.

${ }^{37} L N B, 154$.
} 
Moyano construye una amarga parodia del regreso de los descendientes de los emigrantes finiseculares. Utiliza la figura de un hipotético conde y la enfrenta a sus modestos exiliados. Aquéllos han perpetuado su nobleza y éstos aspiran, aun careciendo de linaje y de título hereditario, a ser reconocidos. Alegarán: "Somos descendientes de los antiguos criados de vuestro bisabuelo", "nosotros somos vuestros criados que regresan", "somos casi los mismos, la

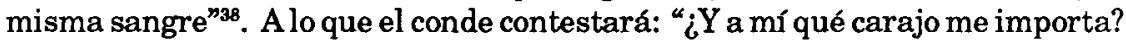
(suponiendo que los condes hablaran así)" ${ }^{\prime 39}$. Esa es otra faz de la desinmigración que el $L N B$ presenta a bocajarro: ¿cuál ha sido el recibimiento que España ha dado a esa "tercera o cuarta generación de españolitos bastardeados que regresan fracasados de las Indias"? ${ }^{40}$.

Moyano no disimula la denuncia, abiertamente proclama el desinterés de la sociedad española hacia la diáspora americana (los navegantes del Cristóforo, setecientos seres humanos que huyen de la violencia, llegan a puerto en el más completo mutismo, olvidados, ignorados) cuando no su franca hostilidad, subrayada por un selloque se imprime en cada uno de los pasaportes, "Prohibido trabajar en España - setecientas veces el sellito como sacando chispas" ${ }^{\text {41. }}$.

Ante esta ingratitud se redondea la tragedia del protagonista y además se fragua la del abuelo. Todo emigrante desea regresar un día a su tierra de origen y este retorno está unido al triunfo, no al fracaso. Consustancial a esta mentalidad es, según Caballero Calderón, la convicción de que desplazarse en el espacio (del viejo al nuevo continente) equivale "a trasplantarse en el tiempo del pretérito al porvenir ${ }^{\mathbf{4 2}}$ siendo ese futuro siempre generoso. Rolando, al volver a Europa expulsado de América, es la transfiguración de ese porvenir frustrado:

... nosotros somos tu fracaso. Este barco no transporta inocentes inmigrantes sino setecientos indeseables, indignos del Cono Sur, que regresan para pedir perdón al señor Conde. Y menos mal que te moriste a tiempo sin saber lo que vendría después, sin saber que volverías tan derrotado como cuando saliste paragủero y leñador, ya no existen en España, ni siquiera tenemos oficio ${ }^{43}$.

\section{EMIGRANTES}

Trasladarse de un país para buscar un futuro mejor en otras geografías es, sin duda, la acción de pérdida más notable que un hombre puede emprender.
${ }^{38} L N B 155$.
39 $L N B 290$.
40 LNB 290
41 LNB 313.
${ }^{42}$ Eduardo Caballero Calderón, Americanos yeuropeos, Madrid: Guadarrama, 1957, 211.
${ }^{43}$ LNB 157. 
Una pérdida en la que siempre se guarda la esperanza de volver ${ }^{44}$. Lo cual no deja de ser un sueño truncado de antemano puesto que si "el exilioes irreversible" en igual o mayor medida lo es la emigración. Esta ilusión del regreso es uno de los componentes fundamentales del desarraigo, pero no el único.

En la narrativa de Moyano los emigrantes ocupan el papel secundario. Su puesto, como un coro situado al fondo del relato, define su función en la trama. El tío o el abuelo extranjero son las referencias familiares que el protagonista posee. Moyano escribe atendiendo a un único segmento social, los desposeídos; por tanto no hay un sólo emigrante en su obra que haya escapado de esta condición. Ninguno ha prosperado económicamente, ninguno ha podido volver al país de origen y ninguno ha olvidado sus sueños, de ahí el resentimiento que rezuman estos personajes:

... el abuelo en un momento dado lloro. Y dijo entre otras cosas que un pobre viejo como él había venido aquí lleno de ilusiones, para tener que morirse algín día sin un solo centavo en el bolsillo46.

Desazón provocada al unirse la frustración de la utopía (soñada en el país de origen y proyectada en el de acogida) con la soledad intrínseca a cualquier proceso de expatriación ${ }^{47}$.

El idioma es uno de los rasgos fundamentales a la hora de indicar el grado de asimilación al que han llegado. Ninguno ha dejado de utilizar su lengua materna con el consiguiente arraigo a una nacionalidad y cultura de la que

\footnotetext{
${ }^{44}$ El retorno como principal meta del transterrado es un tema obligado en cualquier obra que trate la emigracion. Elegimos un pasaje de Miguel Barnet como ejemplo: Nunca desistí de volver a Pontevedra. Esa era una idea fija en mí. Quería volver a ver a mis abuelos, a mi hermana, a mis sobrinos, que no conocía. Era el sueño de todo peninsular. Lo demás es cuento. El que no volvio fuese porque no hizo dinero o lo hizo y cré una familia. Yla familia hala más que unayunta de bueyes" (Gallego,Madrid: AlianzaEditorial, 1987, 97).

${ }^{45}$ Rita Gnutzmann, "Entrevista a Moyano", Hispamérica 46-47 (abril-agosto, 1987): 122. En otra entrevista concedida a Adolfo Casaprima, Moyano explica con una metáfora musical el abismo que abre cualquier ausencia: "Yo he dejado atrás doce años de mi vida ... No sé; es como si a una partitura le faltasen unos compases y yo no pudiera cantarla" Oviedo: El Correo de Asturias, 18 nov. 1988).

${ }^{46}$ Daniel Moyano, "Los mil días", La lombriz, Nueve 64, Buenos Aires, 1964: 22 (citaremos $L L$.).

${ }^{47} \mathrm{La}$ frustración de la esperanza y la soledad son las constantes que señala Ernesto Sábato al referirse a los primeros contingentes inmigratorios que llegaron a Buenos Aires: "En aquel crepúsculo del siglo XIX llegaron a estas playas barrosas multitudes de seres corroídos por la miseria de las aldeas italianas y españolas, polacas, rusas, libanesas ... Venían alentados por la esperanza; los más encontraron otro género de pobreza, pero ensombrecidos por la soledad" (Entre la letra y la sangre. Conversaciones con Carlos Catania, Barcelona: Seix Barral, 1989: 130).
} 
faltan desde hace décadas. Así, el idioma vernáculo se inserta espontáneamente en el discurso del abuelo de «Los mil días» o del tío en «El crucificado». Moyano enfrenta esa conflictiva relación con el paŕs, con el efecto que produce en el niño el cual pertenece a la tercera generación de emigrantes.

El personaje infantil nacido en América observa que el español del abuelo es "casi correcto ${ }^{{ }_{48}}$ o que el tío habla "bastante bien el idioma del país" ${ }^{\text {"49 }}$. "Casi" correcto y "bastante" bueno es el español de la primera hornada inmigratoria, ese es el idioma que escucha el nieto o sobrino argentino, por tanto el personaje protagónico no se ha criado con unas referencias concretas que remitan a una geografía exacta; más bien es la mezcla, la indefinición, la noticia de mundos desconocidos y casi siempre mejores que el suyo, lo que ha marcado sus primeros $a_{n ̃ o s}{ }^{50}$. El niño de Moyano ha crecido en medio del desarraigo, ha escuchado historias que aluden a otros lugares; ha sido testigo atento del paulatino deterioro de las expectativas del pariente; y de este modo ha despertado a la vida

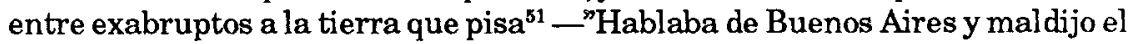
barco y el Río de la Plata. Este era un país de negros y vividores que no querían trabajar ${ }^{752}$. Todas estas claves conducen a la figura final de Matías Bursatti en "La lombriz», un adulto que ha heredado el resentimiento de su padre, emigrante sin fortuna, hacia Argentina ${ }^{53}$.

Por tanto la constante de los emigrantes de esta narrativa radica en la imposibilidad de asimilarse al medio unida a la imposibilidad del retorno. El quedar a caballo entre dos patrias, entre dos culturas, entre costumbres e idiomas diferentes, lejos de enriquecer al personaje son un fardo de desidentidad

\footnotetext{
48 "Los mil días", $L L, 18$.

${ }^{49}$ Daniel Moyano, "La puerta", EM, 13. En la primera redacción Moyano no resalta este sintoma de extranjeria. La emigración no es un factor constante del desarraigo como va a ser en toda su obra posterior, sino, sin más, la condición del argentino. "Su tío era calabrés, mejor dicho lo había sido, porque con treinta años en el país era un argentino como cualquier otro y solo utilizaba su idioma natal para la blasfemia" $(A D V, 51)$.

${ }^{\mathrm{s}} \mathrm{El}$ propio au tor reconoce que la concepción de la argentinidad como algo impuro también marcó los primeros pasos de su identidad: "... yo me crié en el exilio italiano de mi abuelo [...] En un exilio de voces, de exilios contados por otros" (Felipe Navarro, "Encuentro con Daniel Moyano en torno de Libro de navtos y borrascas o los barquitos de la palabra", Novela y exilio, 200).

${ }^{61}$ En una entrevista concedida en 1983, Moyano hace coincidir, de nuevo, sus recuerdos infantiles con el mundo ficcional: "Mi abuelo viví́ cuarenta años en el país y ni un solo día dejo de despotricar contra el", (R. E. Torres, Entrevista a Daniel Moyano, La Semana, Buenos Aires, mayo, 1983: 83).

52 "Los mil días". $L L, 17$.

${ }^{53}$ Matías rememora la frase del tío, "Ya no se puede vivir en este país", y descarga su ira hacia él haciendo hincapié en la imposibilidad del regreso: "Como si alguna vez, alguna remota vez [...] hubiese podido ir a otros paises o presentir siquiera que existieran". Uno de los contertulios de la reunión analiza esta postura de Matías y resuelve: "Eran quizás frases heredadas de su padre, italiano de nacimiento, que jamás pudo hacer una fortuna como deseaba" ("La lombriz", $L L, 100-101$ ).
} 
que los aplasta ${ }^{54}$. Han quedado flotando en la mediana de dos mundos, sin pertenecer a ninguno, y trasmitirán este desarraigo a sus descendientes.

\section{LA CONDICION DEL DESARRAIGO}

"Somos un camalote inmenso de plantas desarraigadas a la deriva" dice Martínez Estrada de la condición del argentino. La metáfora del camalote no puede estar más plena de contenido: plantas que flotan enredadas con otras de diferentes especies y forman, a simple vista, un mapa de islas aisladas entre sí. Esa es la topografía interna de un país cuyas fronteras son símbolo del tránsito. Puertas de entrada para los aluviones inmigratorios de otras épocas y de salida para el éxodo político y económico contemporáneo.

Las “voces” del desarraigo se escuchan en toda la narrativa de Moyano, mediante un tipo de personajes concretos (los exiliados y los emigrantes) y a partir de una situación de extrañamiento global hacia el medio en que viven (condición de la que participan todos los personajes, especialmente los niños).

Los ensayistas americanos han visto en el sentimiento de extranjería uno de los factores primordiales de la alienación general del continente. Ya Sarmiento, a la sazón uno de los impulsores de la emigración a Argentina como arma de progreso, advertía del peligro de una Buenos Aires convertida en "ciudad sin ciudadanos ${ }^{\$ 56}$ merced a que sus habitantes se declaraban extraños al país. Esto producia, evidentemente, un ambiguo sentimiento patrio, una esquizofrénica nacionalidad ${ }^{57}$ :

\footnotetext{
54 Para nuestro planteamiento no hay que olvidar que Moyano no pretende un estudio exhaustivo de la emigración sino que el emigrante es un actor secundario de un ambiente general de desarraigo. La miseria (en los relatos) y la violencia (ETD y $L N B$ entre otras obras) que padecen en América redondeará su sentimiento de extranjería.

${ }^{55}$ Ezequiel Martínez Estrada, Para una revision de las letras argentinas, Buenos Aires: Edit. Losada, 1967, 33.

${ }^{56}$ Domingo Faustino Sarmiento, "EI mito babilónico", en La condición del extranjero en América, Librería "La Facultad", Buenos Aires: Col. Biblioteca Argentina, 1928, 291. (También en Obras Completas, t. XXXVI. Artículo publicado en El Diario, 9, septiembre, 1887).

${ }^{57}$ De las sucesivas oleadas de inmigrantes que llegaron desde las últimas décadas del siglo pasado al Río de la Plata, sólo adquirí la nacionalidad argentina una mínima parte. Gladys Susana Onega señala las razones prácticas de esta postura: los inmigrantes en Argentina gozaban de los mismos derechos que los naturales del país sin las obligaciones de éstos (servicio militar); un clima político inestable y corrupto tampoco avivaba los deseos de nacionalizacion y si fomentaba la indiferencia del inmigrante por los asuntos públicos (La inmigración en la literatura argentina, Buenos Aires: Centro Editor de América Latina, 1982, 19-20). Todo ello crea una postura de no asimilación del país de acogida, es la Argentina para vivir pero no para radicarse que denunciaban dos personajes tan opuestos (y no obstante tan parecidos) como Sarmiento y Martínez Estrada. Los clubes y centros españoles, que tanto proliferaron y cuya labor continúa en América, son buen ejemplo, no sólo del recuerdo ferviente a la tierra que se abandonó, sino de cierta postura de distancia con el país de acogida.
} 
Así viviendo entre dos existencias no ha gozado de la una ni puede gozar de la otra, sin ser ciudadano de ninguna de las dos patrias, infiel a ambas, extranjero en todas partes ${ }^{58}$.

Un siglo después, los males de la "extranjería" no han variado lo más mínimo para Martínez Estrada que denuncia la condición de "huéspedes" y no de "ciudadanos ${ }^{m 59}$ de los naturalizados argentinos; lo cual convierte la república en una abstracta "entidad política" ${ }^{\text {"6o }}$ compuesta por los más variopintos y encontrados sentimientos patrios.

Por esta vena abierta que hace que el emigrado se autoconvierta en extranjero de la tierra natal y de las nuevas geografias ${ }^{61}$ se llega a la parábola evangélica de Murena, América "es destierro ${ }^{\text {"m2 }}$, está poblada por los expulsados del "paraíso" europe ${ }^{63}$. El transterrado y sus descendientes conservarán en la memoria los rastros de la otra tierra - "Cada uno de nosotros es para sí mismo anuncio, nuncio de lo que fue en el paraíso" ${ }^{n 4}$-, lo que forjará un vacío difícil de llenar, al quedar transformado el hombre americano en signo, en "señal de una

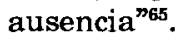

De la ausencia hecha hombre queda, en la obra de Moyano (como en la de Hernández y di Benedetto), una nostalgia más corrosiva aún que la tristeza. La segunda redacción de $E T D$, realizada después de que el autor experimentara la ruda amputación que supone el exilio externo, no hace distinciones entre la expulsión y la emigración porque el autor nunca pretende un análisis político (en todo caso su narrativa es más social) sino una alegoría sobre el hombre y el

\footnotetext{
${ }^{58}$ Domingo Faustino Sarmiento, "La comunidad extranjera", La condición del extranjero en América, op. cit., 77. Artículo publicado en El Nacional, 8 octubre 1855.

${ }^{58}$ Ezequiel Martínez Estrada, Para una revision de las letras argentinas, 33 . El autor añade que los argentinos "habitamos y no radicamos'.

${ }^{60}$ Martínez Estrada, 41.

61 Rómulo Gallegos condensa de manera magistral esta extranjería absoluta en su relato "Los emigrantes". El maestro venezolano traslada a sus personajes al país de origen, cristalizando de este modo el deseo que han avivado durante su larga estancia en América. Una vez allí se encontrarán con lo que ni siquiera habían imaginado: ya no pertenecen al lugar donde nacieron porque sencillamente "así" no era su patria décadas atrás. Además, sus hijos no son libaneses, ni italianos, sino americanos: "Estaban viejos, se arrastraban penosamente por los caminos de la tierra, de aquella tierra que había sido dura y cruel con ellos, pero alli en el corazon del pais, sangre de su sangre corría, transformada, vigorosa y fecunda por los cauces infinitos de la vida [...] La tierra ajena les barrió del corazón el amor a la propia y les quitó los hijos que ellos le dieron" (Obras Completas, Madrid: Aguilar, 1959: 1.353).

${ }^{62}$ Héctor A. Murena, El pecado original de América, Buenos Aires: Sur, 1954, 24.

63 "He aquí los hechos, en un tiempo habitábamos en una tierra fecundada por el espíritu, que se llama Europa, y de pronto fuimos expulsados de ella, caimos en otra tierra, en una tierra en bruto, vacía de espíritu, a la que dimos en llamar América", Murena, 163.

${ }_{64}^{4}$ Héctor A. Murena, La metáfora y lo sagrado,Barcelona: Alfa, 1984, 66.

${ }^{65}$ Murena, 66.
} 
mundo. Desde este punto de vista, ambos tipos de expatriación conducen al desarraigo, a la "ausencia".

El destierro moyaniano no es un hecho de fecha concreta y antiquísima sino múltiple, constante, presente e infinito. En ese crisol de pérdidas, la vida misma es el "exilio" doloroso del reducto de inocencia que fue la infancia - "... la infancia que, como todo el mundo sabe, es la única y verdadera vida; todo lo demás, puro exilio"66 _; y en el concreto caso argentino, Buenos Aires es el "exilio" de Triclinio por su condición de "cabecita negra" portar un "carnet de desubicado" o de "desarraigado" ${ }^{\text {"⿻ }}$ que en resumen es un "certificado de exilio"70 para cruzar las fronteras de La Rioja hacia la capital.

Este panoramaimplica que los personajes de Moyano, ya sean transterrados, emigrados, descendientes de ambos o exiliados, padezcan una melancolía ${ }^{71}$ propia y heredada que traza, en este universo narrativo, un mapa de desazón que se extiende más allá de la expulsión por motivos políticos o económicos ${ }^{72}$.

Los personajes de esta narrativa proclaman que han sido arrojados a un espacio hostil. Algunos exclaman sin dudas, y los más intuyen, que han sido

${ }^{66}$ ETD2, 31. No existe dicha conversación en la primera versión.

${ }_{67}^{6}$ «... resolvió escribirle [Triclinio al presidente de la República] la siguiente carta, como recurso extremo ante la tristeza portuaria y la pobreza de cabecita negra y de exiliado que padecia" (ETD2 43). No aparece dicho párrafo en la primera versión.

68 "El padre Francisco, exhibiendo el raído carnet desubica do que tenía Triclinio, demostró teologicamente que entre desubicado y exiliado apenas habfa diferencia" (ETD2, 35). En la primera versión "El cura [...] no habia mucha diferencia", 36.

${ }^{60}$ "Me darás [le dice Ufa] tu carnet de desarraigado para canjeártelo por uno de huésped en observación" (ETD2, 74). No aparece en la primera versión.

70 "En la estación hubo dificultades, cuando la policia exigio un certificado de exiliado para dejarlo salir de la provincia", ETD2, 35. En la primera version "A último momento [...] salir", 36 .

${ }^{71}$ Moyano trabaja creando un clima de opresión en el que no hay fisura alguna, por eso, como ya hemos apuntado con la figura del pariente emigrante, los personajes secundarios no se escapan de ese ambiente general. Por ejemplo, el casero de la pensión adonde Triclinio vuelve cada día desalentado ante la falta de un lugar para él en la ciudad, no tiene mejor suerte que el músico: "El tono bajo y monocorde de la voz del dueño de la pensión, mortificaba a Triclinio. Después se acostumbró a ver detrás de esa máscara sonora a un hombre desvalido y acabado, melancolico congenito, que sin abandonar su agresividad le regalaba entradas para conciertos y lo mantenía informado de cuanto asunto relacionado con el violín sucediese en el mundo, gracias a las revistas extranjeras que leía en su lengua, alemán ...", ETD2, 40. En la primera versión no aparecen los significativos matices que hemos apuntado, el párrafo queda en una gruesa y ocasional descripción: "Lo mortificó un poco el tono agrio del propietario, que sin embargo resulto un buen tipo: le regalaba entradas para los conciertosy preparaba unos excelentes bifes de chorizo. Tenía el aspecto de un tipo acabado pero contento" (ETD1, 39).

${ }^{72} \mathrm{Si}$ confeccionáramos una lista de los personajes moyanianos que se sienten desterrados al considerar ajeno el lugar en que viven, la gran mayoria de las criaturas que pueblan esta narrativa estarian incluidas en ella. La obra se inaugura editorialmente con el volumen de relatos $A D V$ (1960), en ella los cuentos "La puerta" y "La espera" presentan un 
expulsados de una generosa tierra original. La presencia de un baúl (y sus variantes valija o cofre) aparecen como prueba irrefutable de otra vida feliz. El baúl se relaciona directamente con geografías remotas. Es signo de itinerario, de viaje, de traslado aunque en todos los casos se desconoce el lugar de partida. Así el paraíso se adivina, se da por cierto, pero no se recuerda.

Al estar de paso en todas partes, la vida del desterrado se guarda en ese cofre. En «Los mil días» el abuelo saca de allí las fotografías de los progenitores desconocidos del niño; mientras Peraltaguarda en él todo aquello que demuestre que "él era o tenía algo ${ }^{\text {"73 }}$. Incluso en $L N B$ se considera al barco un "arcón" que, por un lado, transporta hacia Europa a setecientos exiliados americanos, comportándose como un gigantesco contenedor de vidas y recuerdos hasta convertirse en la primera referencia vital para los viajeros; por otro, él mismo debe salvaguardar la memoria de sus navegantes hasta que en un futuro deseado se acabe con las migraciones.

Moyano retoma la populary sarcástica idea de la condición de desarraigados de los pobladores del Río de la Plata - Barco que vale tanto como un imperio

protagonista infantil que desea escapar de la casa del tío y del abuelo, espacio donde se siente abandonado; cuatro años más tarde se publica $L L$, y en el relato que da título a la colección, Matías Bursatti narra la infancia que paso "atrapado" en el hogar de unos parientes; "Después de este destierro" no oculta en su título la temática del mismo; esta vez bajo un marco de represión política, el protagonista lanzará su plegaria al cielo donde está contenida su visión del mundo. El fuego interrumpido (Buenos Aires: Sudamericana, 1967) incrementa el número de relatos cuyo eje temático será el destierro. "El crucificado" y "El perro y el tiempo" eligen la casa del tí; "Otra vez Vañka" se reparte entre la casa del tío y un orfanato-reformatorio, mientras que "Etcétera" expresa el destierro en la casa del tío sin los tintes dramáticos que guardaba en los demás cuentos; en el volumen se incluye de nuevo "La espera"; $E D C$ (1974) propone varias clases de exilio, el del provinciano en Buenos Aires ("Hombres junto al muelle"), en la propia tierra por causa de la intolerancia ("El estuche del cocodrilo") y la miseria ("Cantata para los hijos de Gracimiano" $y$ "Para que no entre la muerte"). O simplemente por pertenecer a un mundo en el que no encuentran acomodo ("Canto de amor y muerte del bombero Cristóbal Miranday").

Por su parte, las novelas Una luz muy lejana y ETD también gravitan sobre el extrañamiento que puede producir la ciudad. La obra del 67 gira en torno a la gran ciudad, que atrae y atrapa en un mismo movimiento; la del 74 (y su posterior versión del 88) localiza exactamente la urbe, Buenos Aires, y entra de lleno en el análisis de una tensión nacional concreta: la hegemonía de la capital sobre el resto de las provincias argentinas.

Esto si atendemos estrictamente a los personajes que formulan la constancia de su destierro y enuncian cuál es el espacio de su condena. Pero el listado se amplía si introducimos esa parte de destierro que supone la incomunicación con los demás, la marginación de todo lo conocido, del mundo establecido y sus formas de convivencia, en definitiva el espacio infinito de reclusión de los inadaptados. Allí estarían relatos como "Artistas de variedades", "Los otros", "La comunión de los seres", "El monstruo", "Nochebuena", "La columna", "La cara", "Clac-clac" y todos los nelatos del volumen Mi música es para esta gente (Caracas: Monte Avila, 1970).

73 "La puerta", $A D V, 54$. 
incaico y una civilización azteca ${ }^{m 4}$, la ironía mordaz se torna en las páginas de este libro en un rictus de amargura cuando el exiliado Rolando, nieto de emigrantes, juega con el contenido de la palabra "vapor": "Vapor, raza y origen"75. "Vapor" por buque-origen pero también "vapor" como condición vital, líquido que se deshace y vaga sin cuerpo anhelando la condensación en una patria verdadera.

Ese es el novedoso y profundo significado que Moyano le aporta al latiguillo popular. El barco es fundación de nuevos horizontes ${ }^{76}$ y a la par despojo y pérdida de los anteriores.

Itinerario, desarraigo, vapor, baúl y barco conducen inevitablemente a la nostalgia (con muchos grados de melancolía) que Sábato señala como el rasgo más señero del carácter argentino y que sin duda es el elemento primordial en la composición de los tipos de esta narrativa. Recorre la obra de Moyano una melancolía absoluta, anterior incluso al nacimiento, puesto que para sentirse desterrado hay que haber poseído antes una tierra $a^{77} \mathrm{y}$, paradójicamente, el personaje protagónico desconoce su hogar original, su patria metafísica.

El desconocimiento del punto de partida hacia el destierro (no sólo el del exilio sino el porqué de una sensación de desarraigo constante) provoca no pocas reflexiones a los navegantes del Cristóforo Colombo y al no encontrar un origen claro lo único que persiste es la imagen de "hombres-barco" 0 " personas "sin lugar fijo que van y vienen. Cuando nos corren de un lugar nos vamos para el otro, y así andamos desde que cruzamos el estrecho de Bering "79.

Moyano refleja una historia de América obstinadamente reiterativa, donde pasado y presente están signados por la migración, el movimiento, el continuo traslado. La parábola llega incluso al "Diario de a bordo" que pretende escribir Rolando, puesto que un diario de navegación, el de Colón, fue el primer documento que descubrió el continente a los ojos europeos. El diario de $L N B$ tiene como meta marcar la ruta para los futuros (y seguros) migrantes, el primer documento americano también era un libro de ruta. Lo continuum del trasiego es entendido por Murena como una situación que coloca al transterrado en medio de una opción excluyente: se elige el recuerdo del "paraíso" perdido, y el espíritu del memorioso queda anclado al pasado o bien se deshace uno de lo

\footnotetext{
${ }^{74} L N B, 27$.

${ }^{75} L N B, 27$.

76 "Hablar de un barco migratorio es ocuparse de cosas fundacionales", $L B N, 27$.

${ }^{77}$ Hecho que ha subrayado Fernando Aínsa cuando estu dia la alienación que el espacio provoca en el héroe de la literatura hispanoamericana. El autor señala que un personaje europeo puede "perderse" o "desaparecer" de su contorno si éste se le muestra extraño, no así el americano ya que "para perderse o para desaparecer necesita de un 'encuentro' previo o 'haber estado' en algún lado antes" (Los buscadores de la utopta. La significación novelesca del espacio Latinoamericano, Caracas: Monte Avila, 1977: 130).

${ }^{78} L N B, 143$.

${ }^{79} L N B, 143$.
} 
anterior y comienza la vida en un presente sin referencias. El lenguaje metafórico de Murena se puebla de alusiones al "viaje" y las "naves". El persistente itinerario de nuevo ${ }^{80}$.

Eduardo Mallea adopta una actitud más positiva. Su intención al buscar el sentido de la argentinidad es hallar la razón y el fin del continuo trasiego. Concibe su país como una nación que se origina, que "nace" constantemente; descubrir las claves de este proceso es, para el autor, comprender el pais, desconocerlas significará "bajo el aspecto de una vida que se perpetúa, el valor de una muerte que se repite" ${ }^{m 1}$. Los personajes de Moyano no alcanzan a comprender el porqué de esos reiterados nacimientos. Es más, "nacer", palabra plena de connotaciones positivas, se traduce en esta narrativa por "originarse" en América, para el emigrante; en Europa, para el exiliado; en la casa del tío, para el niño, y ninguno de estos principios es esperanzador y en ninguno se consigue "matar" lo anterior, el recuerdo es una forma de vida para las criaturas moyanianas.

Aún así, nuestro autor no teoriza; soslaya, por supuesto, el mestizaje como prueba de un origen difuso y misceláneo - $" . .$. con estas caras de Paredes mezclados con Contardis que teníamos los setecientos judíos de la pampa sin pampa"82; “ ¿No ves la cara de trasplantados que tenemos todos?" denuncia la confusa identidad que para el resto del mundo tiene América basándose en el farragoso tema de la denominación _-"América Latina es excluyente, Amerindia impreciso, Hispanoamérica o Iberoamérica no alcanzan a nombrar la totalidad, y por poco casi no tenemos nombre"84.

Después de esas alusiones, el interés de este universo narrativo se sitúa en el vacio que los frecuentes abandonos han ocasionado a sus criaturas. Desde esa desazón, la única certeza es saberse desterrados. Y desde el destierro la fuga es un impulso irreprimible compartido por casi todos los personajes; pero el espacio narrativo es un laberinto sin salida, puesto que si no se conoce el espacio original, el paraiso perdido que se busca, ninguno sabrá hacia donde dirigir la huida.

\footnotetext{
${ }^{80}$ Para vivir en este orden hay que quemar las naves del viaje, hay que desautorizar espiritualmente lo que quedó atrás, pues este es el nuevo mundo, y lo que aquí se hace es una nueva vida que de ninguna forma es continuación de la anterior. Matar o morir: no hay otra alternativa" (El pecado original de América, 24).

${ }^{81}$ Eduardo Mallea, Historia de una pasion argentina, en Obras Completas, Vol I (Buenos Aires: Ediciones Corregidor, 1986), 119.

${ }^{82}$ Daniel Moyano, $L N B, 92$. El $L N B$ está lleno de referencias a la propia literatura, aquí se juega con el título del libro de Alberto Gerchunoff Los gauchos judtos (1910).

${ }^{83} L N B, 142$.

${ }^{84} L N B, 142$.
} 